also discussed. Holton raises the issue in a captivating essay on the origins of the Fermi groups research with slow neutrons in Rome during the 1930s. The decisive experimental step was taken by Fermi himself, when he interposed paraffin between the fast-neutron source and the target. Fermi turned to the paraffin with neither forethought nor announcement. He was guided, Holton writes, by brilliant intuition, a speculative move "below the level of consciousness. In the course of mathematical invention, Henri Poincaré knew similar moments of deep intuition that arrived unbidden, "a manifest sign", he thought, "of long, unconscious prior work".

Holton writes with relish of a conversation on the origins of the uncertainty principle between Heisenberg and Einstein in the mid1920s that Heisenberg recounted to him in 1956. But Holton finds Heisenberg's politics appalling, and rebukes him for his willingness to collaborate with the Nazi regime and for issuing "astonishing exaggerations" about Einstein's role in the atomic-bomb project while claiming that he had declined on moral grounds to build an atomic bomb for Hitler.
Holton rightly insists that the Heisenberg in Michael Frayn's play Copenhagen, who said he knew how to build a bomb but refrained, is a fictional character and ought to be viewed as such.

Holton is dismissive of the postmodern critique of science, saying it holds that the aim of achieving objective truth is unrealizable "because there is no difference between the laws scientists find in nature and the arbitrary rules that govern baseball games. He finds part of its roots in nineteenth-century European romanticism, which was at times scientifically productive. But he also sees shades of it in Hitler's declaration that "there is no truth, in either the moral or the scientific sense. For Holton, truth emphatically exists in both senses. It is clear from these graceful essays that he stands with Rabi, admiring his insistence that science is an essential part of culture, an ennobling activity, a guide to objective thinking and a "unifying force for all of humanity".

Daniel J. Kevles is in the Department of History, Yale University, New Haven,

Connecticut 06520-8324, USA.

\title{
The making of a genius
}

\section{The Creating Brain: The Neuroscience of Genius \\ by Nancy C. Andreasen}

Dana Press: 2005.225 pp. $\$ 23.95$

\section{Mark Lythgoe}

Ever since the first bright spark discovered how to make fire, the recipe for genius has been one of culture's most alluring quests. Yet historically, our conception of genius has been mysterious. The very idea that it could be explained seems to run counter to its essence. From antiquity until the Enlightenment and beyond, genius was seen as an innate trait bestowed by the gods. But as the gods lost their power, it has fallen to others to do the explaining. Even modern science has been reluctant to take up the challenge, as the apparent unpredictability of creative genius seems to elude any singular systemic explanation.

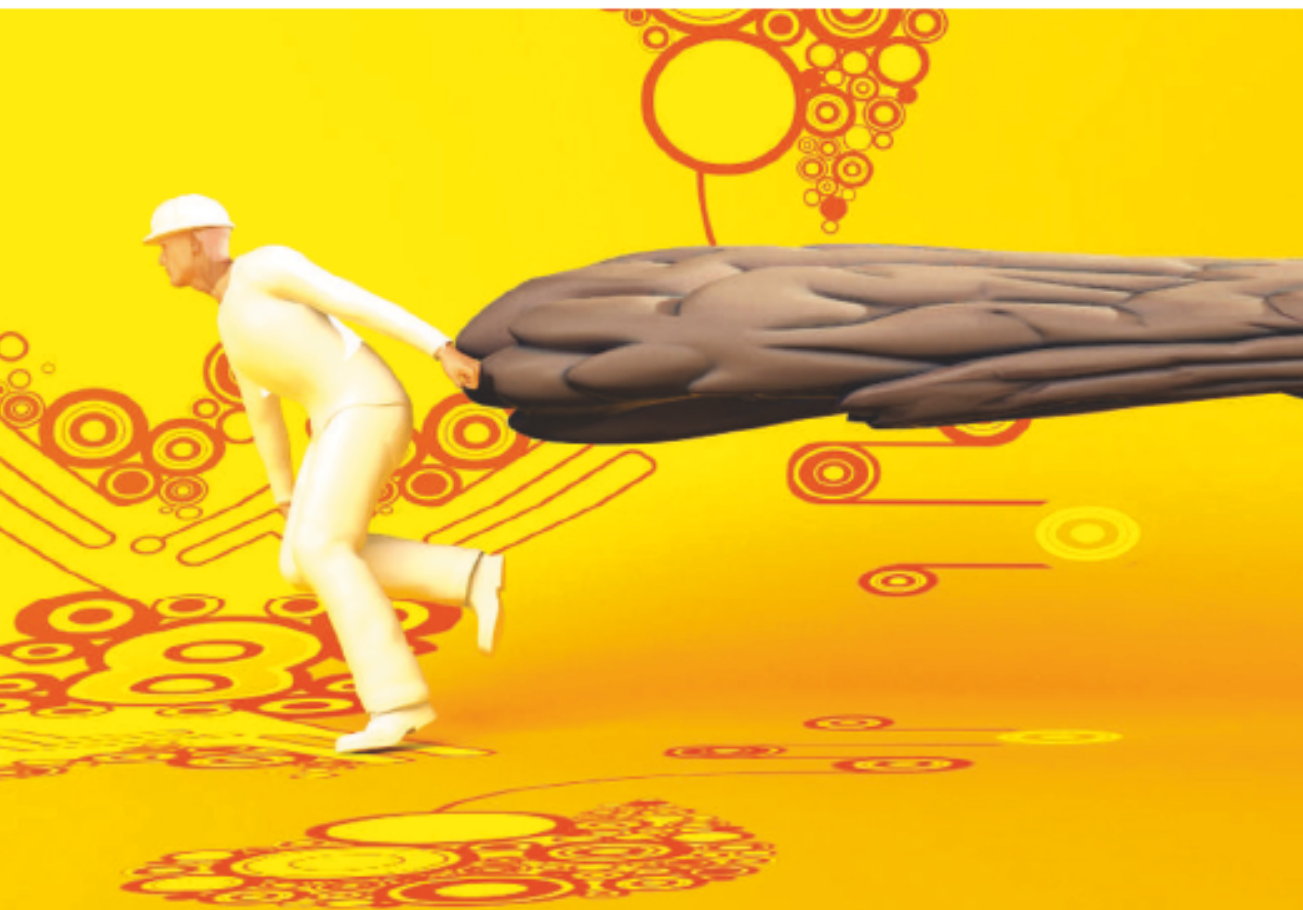

Part of the problem for science has been attempting to distil a working definition of genius that removes its more subjective and untestable historical and cultural associations, while still retaining our idea of it. This is far from easy. One tenet is that a genius must be recognized as such by the relevant experts in the field - but by that reckoning, if Einstein hadn't published his theories, he would have been barred from the title. Despite the many difficulties with investigating genius (hence the mixed results), science has tried to break it down it into components such as intelligence, structure and function of the brain, madness, level of disinhibition, even genetic inheritance.

Because of the somewhat elusive definition of creativity, Nancy Andreasen opts for a case-study approach in her book The Creating Brain. Andreasen is an $\mathrm{MD}$ with a $\mathrm{PhD}$ in Renaissance English literature, which formed the basis for her first book, John Donne (Princeton University Press, 1967). From Mozart to August Kekulé, and Henri Poincaré to Samuel Taylor Coleridge, she unravels the insights, accounts and descriptions of their moments of revelation. After dissecting their multifarious personality traits, she attributes their extraordinary creativity in part to "brains that are more facile at creating free associations", and to contributions from the "unconscious mind". Her accounts suggest that unconscious processes are at work, but as the US writer Gertrude Stein warned us, they cannot be summoned at will: "It takes a lot of time to be a genius, you have to sit around so much doing nothing, really doing nothing." Perhaps that's some comfort for us mere mortals.

No account of creativity would be complete without a departure into the notion that genius and mental illness are inextricably linked. There is a pervasive belief that creativity and bipolar disorder, in particular, have a strong connection - perhaps we like to think that in order to be creative one must, at the very least, have a touch of madness. Andreasen recounts her own experience investigating individuals from the Iowa Writers' Workshop, who to her surprise had an increased incidence of depression, either bipolar or unipolar, suggesting a "relationship between artistic creativity and mood disorders". It is interesting to speculate whether this relationship is causal, is specific to certain subpopulations of mental illness, or whether the arts provide a suitable home for those with a particular illness. Whatever the reason, the link is compelling, and it is easy to produce a list of names that provide anecdotal support. But why do so few of those who are debilitated by bipolar disorder receive the benefits of this extraordinary artistic creativity?

It is well recognized that brain development occurs on a hectic timetable, given that several trillion synaptic connections must be laid down for the brain to function at average levels. During early pregnancy, 250,000 brain cells are created every minute, and this continues at a ferocious rate during infancy, when 
connections form that allow you to crawl, walk and then talk. There is then a process of constant organization and reorganization that continues until early adult life and beyond. This process, known as brain plasticity, is the basis for Andreasen's self-help guide to improved creativity. She advises us to perform mental exercises, explore unfamiliar fields of endeavour, meditate or " ${ }^{\alpha u s t}$ think", practise observing, describing and imagining. And kids must turn off the TV, read, explore the natural world and listen to dassical music. Despite what might seem like reasonable offerings, this section, and maybe others too, could perhaps have been complemented by a reference list to allow some assessment of the arguments and suggestions presented.

Andreasen writes with clarity and ease, interspersing personal and scientific opinion. She makes wonderful connections between the arts and sciences, which surely spring from her background in literature. And she provides a succinct overview of diverse fields of investigation, as well as providing a perspective that reaches beyond the usual approaches to understanding the relationship between creativity and the brain.

Mark Lythgoe is a neurophysiologist in the Radiology and Physics Unit, Institute of Child Health, 30 Guilford Street, London WC1N1EH, UK.

\section{Digging for clues}

\section{Discovering Dor othea: The Life of the \\ Pioneering Fossil-Hunter Dorothea Bate by Karolyn Shindler \\ HarperCollins: 2005. 304 pp. $€ 25$}

\section{Jennifer Clack}

The slightly blurred, somewhat ghostly figure caught in a pose of resolute determination on the cover of this book is a highly appropriate image and captures the essence of the subject. How do you write a biography of someone who left virtually no personal documents, but a wealth of published scientific articles? The author, Karolyn Shindler, faced this problem when she tackled the life of Dorothea Bate, a pioneering female palaeontologist who worked in the first half of the twentieth century.

Bate's interest in natural history and fossils began early, when she was about ten. It seems to have arisen spontaneously, rather than from the influence of any adult around her - this is often the way with palaeontologists and natural historians. The absence of any personal diaries, from any stage of her life, leaves unanswered questions, such as what motivated her initially, and what drove her to continue against a multitude of difficulties. Her initiative in beginning such daunting adventures as expeditions to remote and poorly resourced locations with only sporadic, sometimes unreliable, local support was exceptional, and leaves me feeling inadequate. What's more, it is clear that she had to face parental opposition and relative poverty from time to time. On the other hand, she received appreciative support from professional palaeontologists at the British Museum (Natural History) in London - male, of course - who recognized her unique contributions. If I have a criticism of Shindler's writing, it is that, in the early parts of the story, the difficulties are somewhat overemphasized to become almost tedious, whereas the successes are downplayed.

She was remarkable for more than being a female palaeontologist at a time when the discipline, and its locations, were male dominated. She also pioneered collecting from previously unexplored and almost inaccessible parts of several Mediterranean islands, discovering new species and faunas from the Pleistocene of the area, and demonstrating

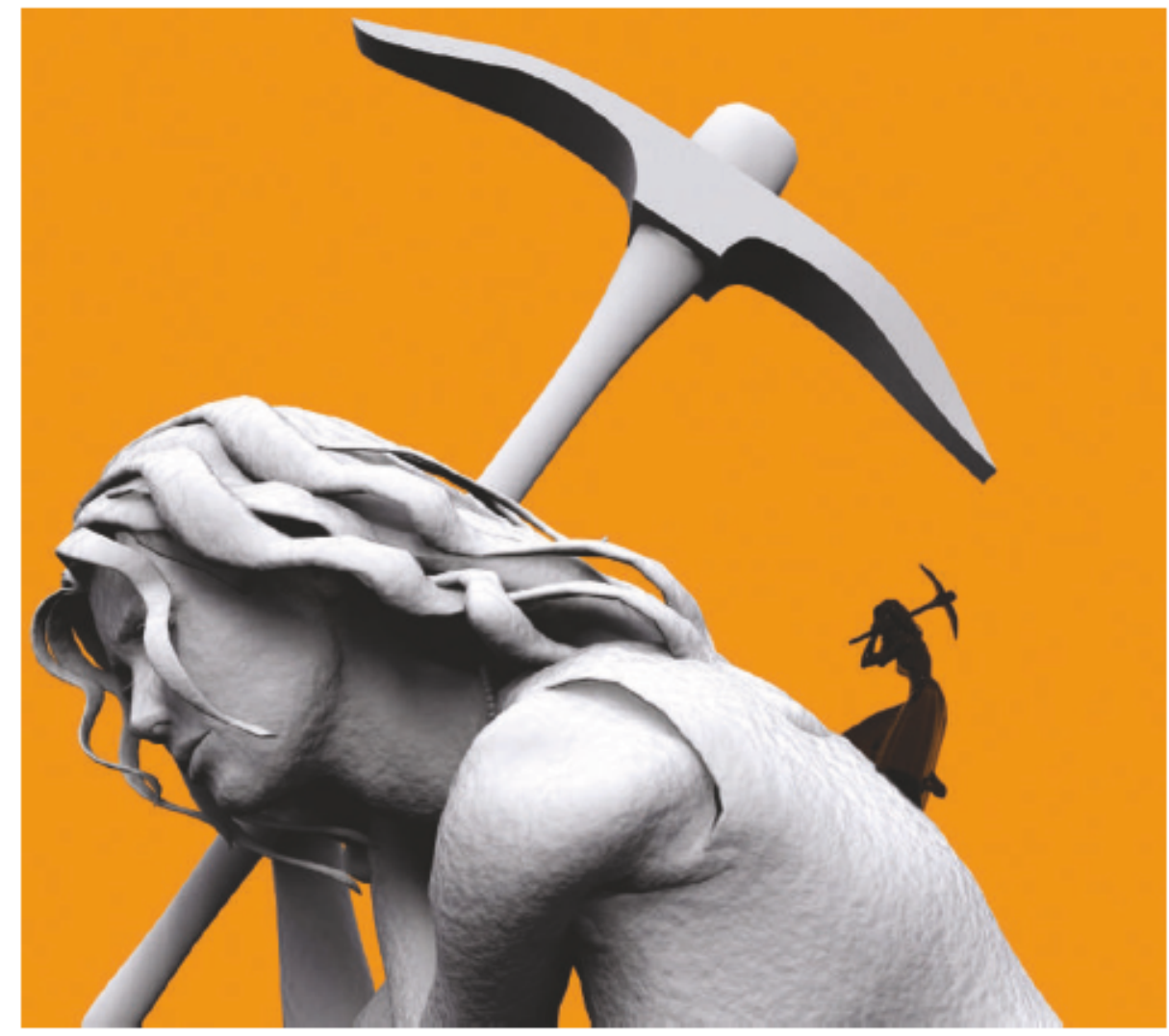

the idea, novel at the time, that island dwarfing of elephants and hippos occurred in parallel on several islands.

As Bate grew in experience and academic stature, she began to integrate evidence from many sites and faunas to infer dimatic changes over recent millennia, at a time when such thinking was in its infancy. She later incorporated this evidence with new finds in archaeology and anthropology to place human remains in their faunal context. She was among the first to recognize that the animals associated with ancient human habitations could shed considerable light on human activities and ecology, and she brought ideas of climate change to bear on human evolution through the Pleistocene. I was previously unaware of her work (my work deals with Palaeozoic fossils), but my colleagues who work on Pleistocene or Quaternary material not only know of her but continue to use the material she collected. Her ideas and techniques were ahead of her time. Her extensive publication record began in 1901 and continued to grow in depth and understanding, and with undiminished energy, until 1955. Despite this, it was not until near the end of her life that she gained permanent paid full-time employment, at the British Museum (Natural History)'s site in Tring.

In her later endeavours, she developed friends and colleagues in the archaeological world, several of whom were also women, and some went on to be pioneers in other respects. Dorothy Garrod, for example, was the first woman professor at the University of Cambridge. It is as though archaeology was already seen as a field in which women could play a significant role.

This biography could perhaps be criticized for its lack of in-depth analysis of the subject's personality or psyche, or that bringing to 